\title{
Relações entre Gestos e Operações Epistêmicas Mediadas pela Representação Estrutural em Aulas de Química e suas Implicações para a Produção de Significados
}

\author{
Relationships between Gestures and Epistemic Operations Mediated \\ by Structural Representation in Chemistry Lessons and their \\ Consequences to the Meaning Production
}

Resumo: Nosso principal objetivo é ampliar a discussão sobre o uso de representação estrutural no ensino de química, por meio da relação entre categorias gestuais baseadas nos estudos de McNeill (2005) e das operações epistêmicas, com a proposição de algumas técnicas de análise qualitativa e quantitativa. Foram analisados dois episódios de ensino nos quais dois professores em formação inicial utilizaram representações estruturais em aulas sobre saponificação e polímeros. O tratamento dos dados foi realizado no software NVivo 10, o que permitiu estabelecer a sobreposição de categorias gestuais e epistêmicas, possibilitando analisar a relação entre elas. A análise nos levou a uma hipótese: o aumento do grau de abstração das operações epistêmicas estaria relacionado com a diminuição do grau de iconicidade das categorias gestuais. Além disso, apontamos desdobramentos da pesquisa para ampliar as análises do movimento discursivo em sala de aula comparadas ao planejamento de ensino, visto que as operações epistêmicas estão relacionadas aos propósitos de ensino do professor.

Palavras-chave: gestos, ensino de química, operação epistêmica, representação estrutural química, produção de significado.

\begin{abstract}
Our main objective is to expand the discussion of the use of structural representation in the chemistry teaching through the relationship between gestural categories based on the contributions of McNeill (2005) and the epistemic operations, for what we purpose some qualitative and quantitative techniques of analysis. Two teaching episodes have been analysed in which two pre-service teachers have used structural representation in lessons about saponification and polymers. The data have been treated with NVivo 10 software that allows the overlap of gestural and epistemic categories, which enables us to analyse the relationships among them. The analysis leads us to one hypothesis: the enhancement of the degree of abstraction of epistemic categories would be related to the decrease of the iconicity of the gestural categories. Besides that, we indicate the spin offs of the research to enlarge the analysis of the discursive movement in the classroom compared with the teaching planning, since the epistemic operations are related to the teaching purposes of the teacher.
\end{abstract}

Keywords: chemistry teaching, epistemic operation, gestures, meaning making, chemical structural representation.

\footnotetext{
Marcelo Giordan (giordan@usp.br), graduação, mestrado e doutorado em Química pela Unicamp e livre docente pela USP, é professor associado da Faculdade de Educação da USP. São Paulo, SP - BR. Arcelino Bezerra da Silva Neto (arcelino.neto@ usp.br), licenciado em Química pela USP, mestrando do Programa de Pós-Graduação Interunidades em Ensino de Ciências da USP, é especialista em laboratório da Faculdade de Educação da USP. São Paulo, SP - BR. Alexandre Aizawa (alexandre.aizawa@ usp.br), bacharel e licenciado em Química pela USP, mestrando do Programa de Pós-Graduação Interunidades em Ensino de Ciências da USP, é professor da rede pública de ensino do Estado de São Paulo. São Paulo, SP - BR.

Recebido em 13/10/2014, aceito em 06/04/2015
} 


\section{Introdução}

No ensino de química, são utilizados diversos elementos de representação como gráficos, tabelas, equações e representações estruturais de partículas para construção de sentidos e significados aos conteúdos conceituais. Dentre esses elementos de representação, a representação estrutural química (REQ) possui destaque ao tratar de aspectos representacionais de entes químicos submicroscópicos, o que caracterizamos como objetos moleculares.

Diversos estudos utilizam a REQ como objeto de pesquisa, sendo amplamente investigado o uso de ferramentas computacionais (Abdoolatiff; Narod, 2009; Bolton et al., 2008; Dori; Barak, 2000; Frailich et al., 2009; Urhahne et al., 2009), níveis de representação da química (Wartha; Rezende, 2011), habilidades de visualização do objeto molecular (Wu et al., 2001; Keig; Rubba, 1993), ênfase na semiótica (Araújo-Neto, 2009; Gois; Giordan, 2007; Souza; Porto, 2010), abordagem histórica (Araújo-Neto, 2007; Viana; Porto, 2007) e estudos sobre uso de REQ no ensino superior (Quadros et al., 2012).

Particularmente, o uso de REQ em sala de aula evoca contribuições dos estudos multimodais que levam em consideração a existência de outros modos de comunicação e representação além da linguagem escrita e falada, uma vez que o professor utiliza-se de suportes específicos na forma de diagramas e objetos tridimensionais. Um modo particular de comunicação e representação é o gesto, por meio do qual o professor utiliza partes do seu corpo, como mão e braço, não apenas para ter atenção dos alunos, mas também para expressar sentidos relacionados ao objeto molecular.

Em estudos recentes sobre a função dos gestos em situações de microensino, observamos a ocorrência de categorias gestuais híbridas (Aizawa; Silva-Neto; Giordan, 2014), conforme já indicava McNeill (2005) em sua contribuição sobre gestualidade e pensamento. Segundo o autor, os gestos podem ser classificados em quatro categorias gestuais: dêiticos, batimento, icônicos e metafóricos.

Os gestos dêiticos (Figura 1) são realizados para indicar algum objeto concreto presente no suporte.

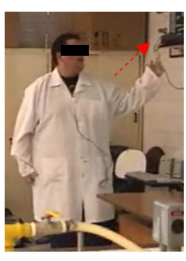

(a)

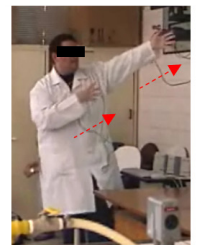

(b)

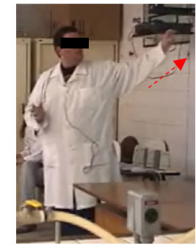

(c)

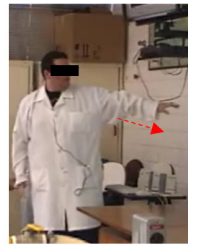

(d)
Figura 1. llustração de gestos dêiticos apontando a tela de projeção com (a) o dedo indicador, (b) as duas mãos abertas, (c) mão curvada delimitando região específica do suporte e (d) mão aberta na horizontal.

Observe que os gestos dêiticos são realizados como forma de apontamentos para o suporte utilizado pelo professor e pode ser caracterizado pelo dedo indicador apontado na direção da tela de projeção ou com a mão aberta indicando a REQ presente na lousa. Um aspecto importante dos gestos dêiticos diz respeito à atenção dos alunos que é compartilhada ora com o professor ora com o suporte da representação.

Os gestos de batimento pontuam a fala do professor, mas também podem ser utilizados para enfatizar algum aspecto do objeto molecular, destacando-o em seu discurso oral.

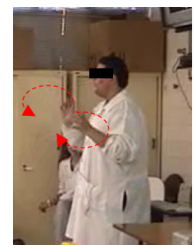

(a)

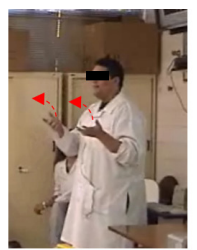

(b)

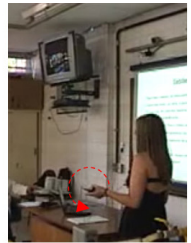

(c)

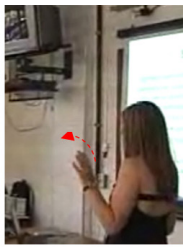

(d)
Figura 2. Ilustração de gestos de batimento com movimento (a) circular de ambas as mãos, (b) de projeção das mãos na direção dos alunos, (c) circular de umas das mãos e (d) projeção de uma das mãos em direção aos alunos.

Na Figura 2(a), o professor movimenta as mãos em círculos, fornecendo ritmo a sua fala. Já em 2(b), ele enfatiza partes de sua fala ao movimentar os braços e as mãos como se estivesse levando uma nova informação aos alunos ou como forma de convite à interação. Os gestos de batimento também indicam aspectos emocionais do professor como, por exemplo, movimentos repetitivos podem caracterizar nervosismo ou ansiedade do professor.

Os gestos icônicos são realizados para descrever o objeto presente de forma concreta no suporte. A materialidade da REQ na lousa, tela de projeção ou modelos plásticos confere ao ente químico aspecto concreto de modo a estabelecer relações de similaridade entre a representação e os gestos.

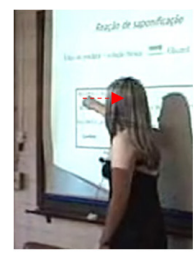

(a)

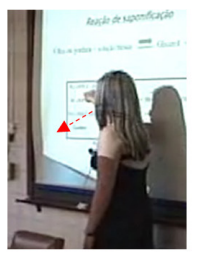

(b)

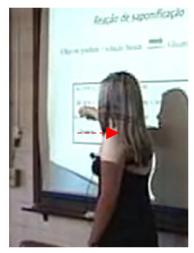

(c)

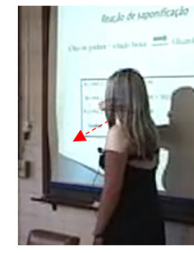

(d)
Figura 3. Ilustração de gestos icônicos para retratar a representação estrutural de um éster.

Nas Figuras 3, a professora realiza gestos icônicos para explicar aos alunos o motivo da formação de três sais de ácido graxo. Para isso, percorre com a mão a representação estrutural do éster, retratando os grupos da cadeia carbônica que serão liberados na interação do material graxo com hidróxido de sódio. A iconicidade está na dimensão da cadeia carbônica que é representada por meio da mão.

Os gestos metafóricos são movimentos que se referem a uma ideia abstrata como, por exemplo, a interação de substâncias em uma transformação química.

$\mathrm{Na}$ Figura 4, o professor realiza diversos gestos para criar uma representação estrutural de traços do metano, ressaltando 


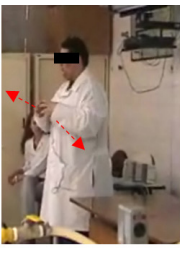

(a)

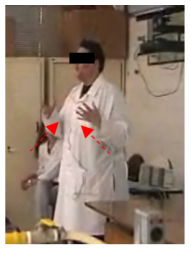

(b)

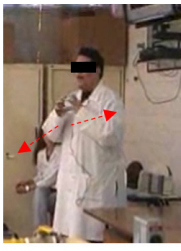

(c)

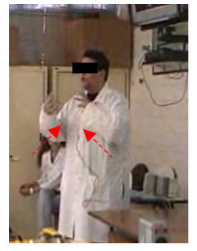

(d)
Figura 4. Ilustração de gestos metafóricos para retratar uma representação estrutural tridimensional.

que a molécula não é uma estrutura plana e que pode ser representada tridimensionalmente, pois possui volume e profundidade.

Nesses estudos, temos verificado uma função central dos gestos pelo professor: eles são parte de um processo de produção de significados estreitamente vinculado a outros modos de representação como sua fala e os próprios suportes da REQ. Na perspectiva sociocultural adotada, a produção de significados está relacionada à ação do professor com os signos como instrumentos de mediação entre o sujeito e o objeto, sendo o emprego funcional dos signos um aspecto fundamental para a construção de conceitos e para o desenvolvimento da habilidade de comunicação (Vigotski, 2009). Nesse sentido, as representações estruturais químicas são ferramentas culturais que os professores utilizam para mediar a construção dos conceitos em sala de aula, sendo utilizadas em suportes como fala, giz e lousa, tela de projeção, objetos plásticos etc.

Neste trabalho, buscamos aprofundar nossa compreensão sobre a multimodalidade na produção de sentidos e significados de conceitos químicos, tendo a REQ como ferramenta cultural ou instrumento de mediação. Especificamente, investigamos os gestos realizados pelo professor e quais relações podem ser verificadas entre elementos gestuais, suportes utilizados, categorias epistêmicas e propósitos de ensino do professor. Portanto, buscamos compreender quais possíveis relações qualitativas e quantitativas existem entre essas categorias e como essas relações podem nos informar sobre a produção de significados relacionados ao uso de representações estruturais químicas. Decorrente desse objetivo, foram desenvolvidas técnicas de análise qualitativa e quantitativa para caracterizar as situações de ensino, sobretudo para interpretar a co-ocorrência de categorias gestuais e epistêmicas. O principal desdobramento dos estudos é contribuir para a discussão sobre o papel da multimodalidade na formação de professores de química. No que diz respeito ao processo de planejamento de ensino, as situações investigadas neste estudo têm como referência o Modelo Topológico de Ensino (Giordan, 2013), constituído à luz da teoria sociocultural de Vigotski (2009) e da ação mediada de Wertsch (1998).

A seguir, apresentamos uma discussão sobre a natureza dos gestos, suas funções no ensino de ciências e, logo após, um panorama das situações de construção dos registros e dados em sala de aula.

\section{Quadro teórico}

\section{A importância dos estudos gestuais}

Kendon (2004), em um panorama histórico sobre estudos da gestualidade, relata o interesse nas ações visíveis do corpo como suporte do enunciado pioneiramente da tradição ocidental com os gregos e romanos, por volta do século XVI, até a consolidação dos estudos sobre os gestos como um campo de pesquisa, no século XX. No século XVII, o autor destaca contribuições de estudos da ação visível com vistas a caracterizar a formação básica para uma linguagem universal. Desdobramentos de estudos no século XVIII possibilitaram aprofundamentos sobre a origem da linguagem e da linguagem gestual, principalmente relacionados à linguagem dos surdos e mudos. No século XIX, o autor enfatiza que os aportes de outras áreas de conhecimento como a antropologia e a psicologia trouxeram diversas contribuições, mas no final desse século, houve estagnação das pesquisas, que foram retomadas somente na década de 1970. De acordo com esse autor, neste século, houve crescimento de estudos sobre os gestos e culminou na realização de diversos congressos e a consolidação da área como um campo de pesquisa.

Kendon (2004) destaca quatro pontos que projetaram o crescimento do interesse em estudos sobre gestos. Em um primeiro momento, o autor informa que gestos e discursos são inter-relacionados e parecem ser oriundos do mesmo processo, mormente, relacionando-os ao desenvolvimento das tecnologias de registro audiovisual. $\mathrm{O}$ autor levanta questionamentos sobre a forma como o gesto e a fala são produzidos, pois podem ser compreendidos como formas de expressões integradas e constituídas pelo mesmo mecanismo, mas também podem ser concebidos como formas separadas de produção de sentidos e a integração ocorre devido a um objeto comum entre eles.

"[...] um exame fechado da coordenação dos gestos e a fala sugere que as duas formas de expressão são integradas, produzidas juntas sob a orientação de um objetivo comum. Isto porque são expressões de duas formas de pensamento que são originadas como únicos, em processo interno? Ou são elas integradas como consequência de como a pessoa, engajada na produção do enunciado, adapta dois modos separados de expressão e os combina em um único objetivo retórico?" (Kendon, 2004, p. 2) [Tradução nossa]

O segundo destaque está no processo de comunicação, no qual os gestos e a fala se alternam como uma conjunção entre eles. Segundo Kendon (2004), a microanálise da interação face a face nos processos de comunicação mostra que as ações visíveis do corpo, por meio do qual os gestos são expressos, 
são importantes para o processo de interação e comunicação, destacando a combinação entre gesto e fala.

Estudar os gestos por serem formas de expressão universais e naturais aparece como terceiro fator de interesse. $\mathrm{O}$ autor indica que apesar de os gestos parecerem espontâneos ou articulados por um indivíduo, eles são regulados e sujeitos a uma convenção social.

"O estudo dos gestos, assim, parece nos prometer caminhos especiais nas formas individuais de expressão e transformação por processos sociais e códigos comunicativos socialmente compartilhados." (Kendon, 2004, p. 3) [Tradução nossa]

Como quarto fator de interesse, indica-se o reavivamento, em meados do século $\mathrm{XX}$, dos estudos sobre a origem e o desenvolvimento da linguagem, inclusive do ponto de vista filogenético. Diante do relato dos irmãos Gardners sobre o sucesso em ensinar linguagem de sinais para um chimpanzé, Hewes (1973 apud Kendon, 2004, p.74) sugeriu que a primeira forma de linguagem poderia ser a gestual.

No ensino, os estudos de Gilbert (2010) caracterizam o gesto como uma metavisualização e apontam para a pouca exploração do uso dos gestos em classe como sendo uma dificuldade de detecção diante da complexidade dos movimentos corporais em salas de aula e laboratórios. Ping e Goldin-Meadow (2010) estudaram os gestos e a fala pela perspectiva das discrepâncias, na qual ambos modos de comunicação nem sempre se apresentam sincronizados. A quantificação dessas diferenças contribuiria para a compreensão dos processos cognitivos. Já Pereira e colaboradores (2013) estudaram os gestos a partir das categorias de Kendon, dos gestos referenciais e pragmáticos em aulas de química do ensino superior, acrescidas dos catchments, os gestos recorrentes, uma forma que se repete ao longo das aulas pelo professor, presentes em McNeill.

O estudo da multimodalidade no campo do ensino de ciências é uma maneira de entender a produção e a circulação de signos que são negociados a partir das interações sociais, mediadas pelos recursos semióticos (Martins; Piccinini, 2004; Kress et al. 2001). Os modos semióticos abrangem tanto o verbal como o não verbal com potencial geração de significados. Quadros e Mortimer (2010) analisaram os gestos em termos de sua classificação em situações de ensino envolvendo professores experientes, bem como analisaram os processos epistêmicos, levando em consideração a semiose específica da sala de aula de ensino superior.

\section{A relação entre operações epistêmicas e as categorias gestuais}

Segundo Jimenez-Aleixandre e colaboradores (1998), as operações epistêmicas surgem das práticas epistêmicas e sua definição relaciona diferentes áreas de conhecimento, conforme:
"Operações epistêmicas: procedimentos de explicação, relações causais, analogias, comparações etc. que podem ser interpretadas como sendo específicas do domínio científico, paralelamente ao que foi proposto por Pontecorvo e Girardet (1993) para as ciências sociais em particular a História." (Jimenez-Aleixandre et al., 1998, p. 4)

Kelly (2005) define prática epistêmica como os meios de uma comunidade propor, justificar e avaliar quando seus integrantes legitimam o conhecimento da estrutura disciplinar. É nesse sentido que Silva (2008) considera as operações como uma ação de tais práticas. Em nossos estudos, as operações epistêmicas estão relacionadas aos propósitos de ensino do professor, especificamente àqueles que são planejados e emergem nas atividades de ensino (Giordan, 2013).

Em nossos estudos, temos utilizado as seguintes operações epistêmicas adaptadas de Silva e Mortimer (2010): descrição, descrição molecular, explicação, generalização, definição, comparação, classificação e exemplificação. A descrição é compreendida como a caracterização de eventos. Já a descrição molecular é uma caracterização do ente molecular. A explicação estabelece relações causais entre fenômenos e conceitos. A generalização é a operação em que descrições e explicações não dependem de um contexto ou sistema específico. Segundo Silva e Mortimer (2010), a generalização é uma forma de descontextualização. A definição refere-se a algo que é aplicável a vários contextos. Já a comparação é a identificação de semelhanças e diferenças entre fenômenos específicos, enquanto a classificação está relacionada ao agrupamento por similaridade e a exemplificação leva a um sistema específico.

Em nossos estudos, temos investigado a relação entre operações epistêmicas e categorias gestuais na busca de padrões de similaridade e diferenças. Do ponto de vista epistêmico, sabe-se que o movimento da descrição molecular para a generalização e a definição é um movimento de abstração, pois inicialmente o contexto é específico e relacionado ao mundo dos objetos e fenômenos, e passa a ser empregado em outras situações em referência ao mundo das teorias e modelos. Outro movimento observado diz respeito à fronteira entre o icônico e o metafórico presente na análise gestual, pois a classificação leva em consideração aspectos imagéticos do gesto, que pode indicar o aumento da sua característica icônica - ou seja, a relação de similaridade com o suporte de representação - e a diminuição da característica metafórica - ou seja, a abstração ante o que está representado.

Sugerimos, por meio da Figura 5, que os movimentos epistêmicos estão diretamente relacionados aos gestos metafóricos e icônicos. As operações de definição e de generalização estariam mais relacionadas com os gestos metafóricos, enquanto as operações de explicação e de descrição molecular estariam mais relacionadas aos gestos icônicos. A categorização gestual em icônico ou metafórico é uma forma de indicar, 
respectivamente, relações mais concretas e mais abstratas. $\mathrm{O}$ borramento dessas fronteiras categóricas é condição empírica constatada, mormente, nas análises gestuais de uso da REQ na sala de aula, o que indica um possível contínuo entre uma e outra categoria gestual.

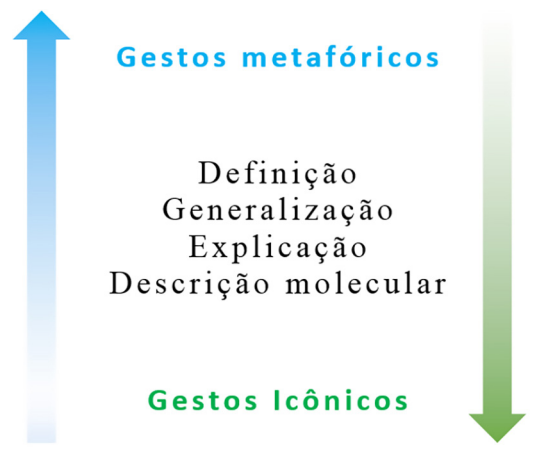

Figura 5. Movimentos epistêmicos no uso de representações estruturais e as categorias de gestos metafóricos e icônicos.

Assim, nossas principais questões a serem respondidas neste artigo são: quais as relações existentes entre as quatro categorias gestuais de McNeill e as operações epistêmicas? Como essas relações podem ser analisadas de forma quantitativa? Quais são as implicações para o ensino a partir das características qualitativas e quantitativas dessas relações?

\section{Procedimentos metodológicos}

O percurso metodológico consiste do registro audiovisual de minicursos oferecidos a alunos de ensino médio da rede estadual paulista no ano de 2012. Licenciandos da disciplina Metodologia do Ensino de Química da Faculdade de Educação da Universidade de São Paulo elaboraram sequências didáticas e desenvolveram-nas durante oito aulas no formato de minicurso na própria faculdade de acordo com os fundamentos teóricos do Modelo Topológico de Ensino (Giordan, 2013). Neste ano, foram realizados quatro minicursos, dos quais foram selecionados dois deles que apresentaram maior presença da representação estrutural química durante as aulas: Sacolas plásticas e Sabões e detergentes.

Após o registro, foram produzidos mapas de episódios para a escolha de um com maior frequência de uso da representação estrutural, classificando-os em relação às categorias gestuais, epistêmicas, de suporte e proxêmicas. Além dessas categorias, também foram classificados os propósitos do professor, que foram inicialmente descritos na sequência didática e posteriormente observados nas sequências discursivas.

Como o foco dessa pesquisa é o professor utilizando representações estruturais, foi selecionado um episódio de cada minicurso, no qual o professor empregou representações estruturais e mobilizou gestos relacionados a diferentes modos gestuais de referência a elas.

Para a codificação do registro audiovisual, foi utilizado o software NVivo 10, software desenvolvido pela empresa QSI International (http://www.qsrinternational.com) para auxiliar em pesquisas qualitativas e mistas, que possibilita sobrepor diferentes categorias. Na Figura 6, verifica-se a codificação de um segmento de 1 minuto e 35 segundos do minicurso Sabões e detergentes, cujas codificações das operações epistêmicas são: descrição (azul claro), explicação (verde), definição (roxo) e descrição molecular (laranja), além dos gestos de batimento (amarelo), dêiticos (vermelho) e metafóricos (azul celeste).

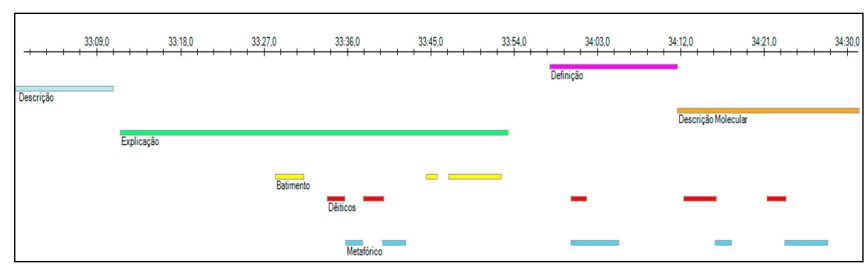

Figura 6. Diagrama de codificação do software Nvivo 10 ilustra as operações epistêmicas e os gestos realizados no segmento de 1 minuto e 35 segundos para a professora.

Observa-se a sobreposição da operação epistêmica explicação com os seguintes gestos: três de batimento, dois dêiticos e dois metafóricos. De forma semelhante, podem ser verificadas outras sobreposições, cujas combinações de categorias, obtidas em relatórios do software, fornecem matrizes contendo as quantidades de sobreposição dessas categorias.

As categorizações de gestos, operações epistêmicas, suportes e propósitos foram desenvolvidas por um processo de análise independente por pares, seguida de discussão dos resultados, até se atingir um consenso.

\section{Resultados e discussão}

\section{Seleção de sequências discursivas}

Durante a elaboração do minicurso sobre sacolas plásticas, os professores formularam uma problematização considerando uma lei que limitava e impedia a distribuição desses materiais pelo comércio. A partir dela, foram endereçadas questões sobre os tipos de lixos, os tipos de plásticos, a forma como os diversos polímeros são obtidos até o momento em que temos o episódio chamado de representação de fórmulas. Nesse momento, o professor (P1) apresentou diferentes formas de representação estrutural, utilizando a lousa e a tela de projeção. A aula teve o intuito de introduzir uma atividade em laboratório de informática, na qual os alunos manipularam representações estruturais em computador. Nesse episódio, foram observadas as sequências discursivas conforme o Quadro 1, suas respectivas durações e frequências de categorias gestuais e epistêmicas.

No minicurso sobre sabões e detergentes, foram problematizados os impactos da utilização, bem como os processos histórico e industrial. O episódio selecionado para a análise é a parte molecular cujas sequências discursivas estão no Quadro 2 
Quadro 1. Tempo de duração e frequência de categorias nas sequências discursivas do minicurso Sacolas plásticas.

\begin{tabular}{|c|c|c|c|c|}
\hline \multirow{2}{*}{ Ordem } & \multirow{2}{*}{ Sequência discursiva } & \multirow{2}{*}{ Duração (mm:ss) } & \multicolumn{2}{|c|}{ Frequência de categorias } \\
\hline & & & Gestuais & Epistêmicas \\
\hline 1 & Apresentação do episódio & 00:29 & 3 & 1 \\
\hline 3 & Função orgânica OH & $00: 21$ & 3 & 3 \\
\hline 4 & Diferenças entre representações & $01: 30$ & 32 & 9 \\
\hline 6 & Explicando a fórmula espacial & $02: 12$ & 22 & 6 \\
\hline 7 & Apresentando o Programa Jmol & $00: 54$ & 13 & 3 \\
\hline 8 & Representações no Jmol & 01:04 & 16 & 4 \\
\hline 9 & Modelos de representação & 03:06 & 35 & 10 \\
\hline 10 & Iniciando a manipulação no computador & 01:21 & 3 & 2 \\
\hline
\end{tabular}

Quadro 2. Tempo de duração e frequência de categorias nas sequências discursivas do minicurso Sabões e detergentes.

\begin{tabular}{|c|c|c|c|c|}
\hline \multirow{2}{*}{ Ordem } & \multirow{2}{*}{ Sequência discursiva } & \multirow{2}{*}{ Duração (mm:ss) } & \multicolumn{2}{|c|}{ Frequência de categorias } \\
\hline & & & Gestuais & Epistêmicas \\
\hline 1 & Produção do sabão & $01: 57$ & 7 & 5 \\
\hline 3 & Levantamento de ideias sobre química orgânica & $00: 44$ & 0 & 1 \\
\hline 4 & Reação de saponificação & $02: 33$ & 17 & 3 \\
\hline 6 & Polaridade de ligação & $01: 49$ & 15 & 5 \\
\hline 7 & Polaridade na molécula do sabão & 01:47 & 18 & 4 \\
\hline 8 & Polaridade e interação das partículas & 01:09 & 9 & 3 \\
\hline 9 & Formação de micelas & 03:06 & 30 & 7 \\
\hline 10 & Resolução de questões & $01: 56$ & 2 & 7 \\
\hline
\end{tabular}

com suas respectivas durações e frequências de categorias. A professora (P2) teve o intuito de desenvolver uma explicação com os alunos para o fato de o sabão limpar. Assim, ela fez um levantamento de concepções dos alunos, desenvolveu o conceito de polaridade e finalizou com a resolução de questões.

Os Quadros 1 e 2 apresentam dados quantitativos gerais de cada episódio selecionado para a análise. Um exame comparativo deles indica maior incidência de gestos de $\mathrm{P} 1$ em relação a P2. Da mesma forma, a ocorrência de operações epistêmicas por P1 é maior em um período de tempo aproximadamente igual. A seguir, apresentamos uma análise com transcrições de falas dos professores e posteriormente uma análise das relações obtidas entre as categorias gestuais e epistêmicas.

\section{Hibridização gestual}

A análise gestual deve levar em consideração a possibilidade de sobreposição categórica (Aizawa; Silva-Neto;

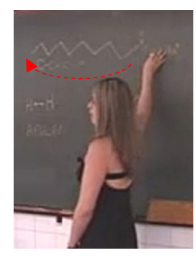

(a)

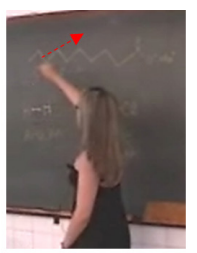

(b)

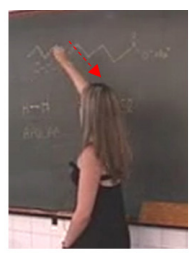

(c)

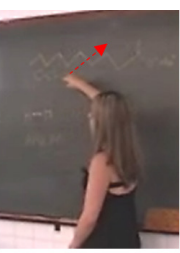

(d)
Figura 7. Exemplo da hibridização icônico/metafórico em referência à cadeia carbônica.

Giordan, 2014), na qual os gestos possuem características de duas categorias.

$\mathrm{Na}$ Figura 7, P2 explica que a cadeia carbônica pode ser representada na forma de traços e percorre essa cadeia com a mão como se estivesse desenhando a representação estrutural presente na lousa. O gesto apresenta, portanto, aspecto icônico por ser semelhante à representação utilizada pela professora. No entanto, esta utiliza outro suporte (fala) para caracterizar uma representação estrutural de traços que ilustra 
os átomos de carbonos e hidrogênios da molécula, cujo elevado caráter de abstração confere aspecto metafórico ao gesto (Quadro 7).

07 - P2: Esse aqui não é igual àquela molécula que a gente viu no (inaudível) slide?

08 - P2: só que invés de tá carbono hidrogênio carbono hidrogênio

09 - P2: eu coloquei umas setinhas para ficar mais fácil. Tudo bem?

Assim, os gestos realizados pela professora são classificados como híbridos icônicos/metafóricos.

Na Figura 8, temos outro exemplo da hibridização de gestos icônicos/metafóricos. Nesse caso, a professora representa com as duas mãos o fato de o átomo de cloro atrair o par de elétrons da ligação para perto dele.

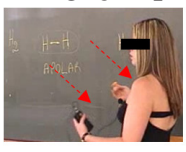

(a)

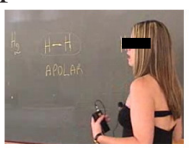

(b)

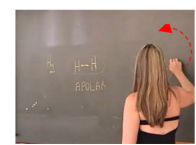

(c)

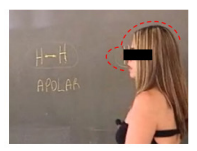

(d)
Figura 8. Exemplo da hibridização icônico/metafórico em referência à nuvem eletrônica.

Observa-se que o gesto possui aspecto metafórico uma vez que a nuvem eletrônica não está representada no suporte lousa. No entanto, a iconicidade aparece logo em seguida ao gesto no momento em que a professora desenha a nuvem eletrônica do cloreto de hidrogênio ao redor dos átomos de hidrogênio e cloro.

Outra sobreposição categórica que ocorre no episódio diz (a)

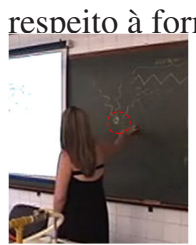

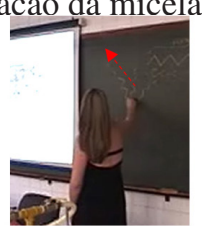

(b)

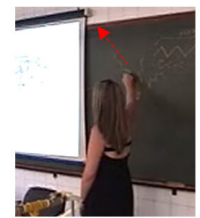

(c)

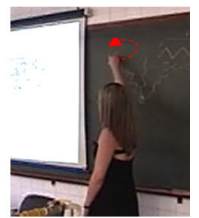

(d)
Figura 9. Exemplo da hibridização icônico/metafórico em referência à polaridade da micela.

Na Figura 9, a professora representa, por meio de fala e gestos (a), a parte interna da micela, em seguida (b) e (c), percorre a cadeia carbônica apolar até chegar à região polar. $\mathrm{O}$ aspecto icônico fica nítido na representação que ela cria do interior da micela ao circular com a mão e também quando percorre a cadeia carbônica. $\mathrm{O}$ aspecto metafórico refere-se à relação de polaridade da micela que não está representada no suporte utilizado.

\section{Codificação em operações epistêmicas e gestos}

Para a nossa análise, consideramos as operações epistêmicas (comparação, exemplificação, classificação, descrição, descrição molecular, generalização, explicação e definição), cujos exemplos encontram-se nos Quadros de 3 a 10. A mudança de turno foi realizada a partir da presença de gestos e modificação de operações epistêmicas como no Quadro 4, o turno (sd06.02) que diz respeito à sexta sequência discursiva (sd06) do episódio e o sequenciamento do turno (02). Em seguida, são indicadas as transcrições, as categorias gestuais e as operações epistêmicas realizadas.

Na sequência discursiva do Quadro 3, P2 classifica os tipos de representações estruturais que estão na tela de projeção como substâncias orgânicas (representação estrutural do triacilglicerol) e substâncias inorgânicas (hidróxido de sódio). Nessa situação, não existem gestos, apenas a fala e o suporte de tela de projeção.

Na sequência discursiva do Quadro 4, o professor destaca aspectos da angulação do objeto molecular (OM) e a presença de átomos de hidrogênio para comparar diferentes representações estruturais presentes na tela de projeção. Além isso, utiliza-se de gestos de apontamento (dêiticos) para orientar a atenção dos alunos para as diversas representações.

No Quadro 5, o professor está explicando a dificuldade de representar aspectos tridimensionais do $\mathrm{OM}$ em duas dimensões. Em seguida, utiliza uma maneira de desenhar o cubo em profundidade para exemplificar formas de ilustração e para construir sentidos a elementos das representações estruturais, cunhas preenchidas e tracejadas, por exemplo, que ilustram aspectos tridimensionais do $\mathrm{OM}$.

Na sequência discursiva do Quadro 6, a professora descreve as características do sabão que será obtido em função do íon presente na estrutura, podendo ser um sabão mais duro quando possui átomos de sódio na estrutura ou um pouquinho mais mole

Quadro 3. Codificação da operação epistêmica classificação no minicurso Sabões e detergentes.

\begin{tabular}{|l|l|c|c|}
\hline Turno & \multicolumn{1}{|c|}{ Transcrição - classificação } & Gestos & Op. epistêmicas \\
\hline & $\begin{array}{l}\text { P2: Vocês estão vendo ali que é um misto de representação de } \\
\text { substâncias orgânicas com substâncias inorgânicas. Cadeia linear } \\
\text { grande com vários carbonos, coisas que vocês costumam ver }\end{array}$ & & \\
sd02.12 & $\begin{array}{l}\text { em química orgânica, vocês já devem ter visto alguma coisa de } \\
\text { nomenclatura orgânica. }\end{array}$ & Sem gestos & Classificação \\
& A: Não & & \\
& P2: Alcanos/ & & \\
\hline
\end{tabular}


Quadro 4. Codificação da operação epistêmica descrição no minicurso Sacolas plásticas.

\begin{tabular}{|c|l|c|c|}
\hline Turno & \multicolumn{1}{|c|}{ Transcrição - comparação } & Gestos & Op. epistêmicas \\
\hline sd06.01 & P1: Então, nessas estruturas, o que tem de diferente nelas? & Dêitico \\
\hline sd06.02 & $\begin{array}{l}\text { P1: Nessa primeira, olha aquele carbono como ele está ali. Aquelas } \\
\text { angulações... esses hidrogênios ligados, eles já tentam mostrar um } \\
\text { tetraedro. }\end{array}$ & Dêitico & Comparação \\
\hline sd06.03 & $\begin{array}{l}\text { P1: Então tem um tetraedro sendo formado ali na ponta, tem um } \\
\text { tetraedro tentando se formar ali no meio. }\end{array}$ & Dêitico \\
\hline
\end{tabular}

Quadro 5. Codificação da operação epistêmica exemplificação no minicurso Sacolas plásticas.

\begin{tabular}{|c|c|c|c|}
\hline Turno & Transcrição - exemplificação & Gestos & Op. epistêmicas \\
\hline sd04.19 & P1: Mesmo assim, a gente ainda pode tentar representar & Batimento & \multirow{2}{*}{ Generalização } \\
\hline sd04.20 & P1: uma estrutura $3 d$ em $2 d$ & Batimento & \\
\hline sd04.22 & P1: vocês já desenharam um cubo? & Sem gestos & \multirow[t]{2}{*}{ Exemplificação } \\
\hline sd04.23 & P1: Vocês colocam eles em posição de profundidade. & Icônico & \\
\hline
\end{tabular}

Quadro 6. Codificação da operação epistêmica descrição no minicurso Sabões e detergentes.

\begin{tabular}{|c|c|c|c|}
\hline Turno & Transcrição - descrição & Gestos & Op. epistêmicas \\
\hline sd01.05 & $\begin{array}{l}\text { P2: A gente vai dar uma olhada. Se a gente tiver no } \\
\text { sabão, na estrutura, o sódio, ele vai formar um sabão mais } \\
\text { duro. Aquele sabão em pedra, mais duro, tem sódio. } \\
\text { Se tiver o potássio, ele vai ficar um pouquinho mais mole. Eu acho que } \\
\text { a gente vai fazer com o potássio. }\end{array}$ & \multirow{3}{*}{ Sem gestos } & \multirow{3}{*}{ Descrição } \\
\hline sd01.06 & P3: Com o sódio. & & \\
\hline sd01.08 & $\begin{array}{l}\text { P2: O sabão é fabricado a partir de gordura... ou óleo. Tanto faz se eu } \\
\text { usar um óleo de cozinha ou gordura animal, os dois vão (inaudível) } \\
\text { fabricar o sabão. }\end{array}$ & & \\
\hline
\end{tabular}

quando estiver presente o potássio. Destaca com dúvida o tipo de sabão que será produzido, sendo corrigida em seguida por outro licenciando (P3).

A professora também destaca quais as substâncias necessárias para a fabricação do sabão como, por exemplo, gordura ou óleo. Trata-se, portanto, de caracterizar as substâncias participantes da reação e também a propriedade dos produtos (dureza) da reação.

Em outro momento da aula, ela desenha na lousa uma representação estrutural semelhante à Figura 10 e realiza uma descrição molecular conforme destacado no Quadro 7.

No Quadro 7, apresentamos a transcrição do trecho e a codificação da operação epistêmica descrição molecular e dos gestos.

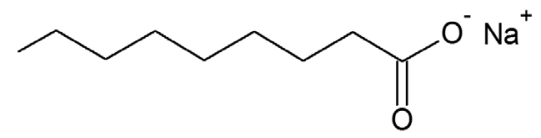

Figura 10. Representação estrutural de traços desenhada na lousa pela professora.
A sequência discursiva ilustrada no Quadro 7 diz respeito a uma tradução que a professora faz do $\mathrm{OM}$ ao reescrever a representação estrutural na forma de traços ou setinhas (Figura 10) para descrever em seguida os átomos de carbono, hidrogênio e oxigênio. Durante a descrição molecular, a professora realiza um gesto dêitico/metafórico para indicar as pontas ou a junção dos traços que representa um átomo de carbono ligado a dois átomos de hidrogênio. Nesse caso, a caracterização é da representação estrutural e, portanto, diferencia-se da descrição que não se refere ao OM. Verificase um hibridismo gestual dêitico/metafórico no turno 05 , porque a professora aponta para o $\mathrm{OM}$, atribuindo uma referência metafórica, pois os dois hidrogênios ligados não são representados no OM. No turno 08 , ela novamente emprega o gesto híbrido dêitico/metafórico para referir-se a ligação entre os átomos de carbono e os átomos de hidrogênio. Já o gesto híbrido icônico/metafórico no turno 09 refere-se ao OM que está representado em lousa com o dedo indicador direito para cima e para baixo, assemelhando-se à representação de traços. 
Quadro 7. Codificação da operação epistêmica descrição molecular no minicurso Sabões e detergentes.

\begin{tabular}{|c|l|c|c|}
\hline \multicolumn{1}{|c|}{ Turno } & \multicolumn{1}{|c|}{ Transcrição - descrição molecular } & \multicolumn{1}{|c|}{ Gestos } & Dêitico \\
\hline sd07.03 & $\begin{array}{l}\text { P2: No caso do sabão, ele não vai ter vários carbonos?/ } \\
\text { A: Inaudível. }\end{array}$ & \multirow{2}{*}{ Dêitico } \\
\hline sd07.04 & $\begin{array}{l}\text { P2: Então eu tenho vários carbonos. } \\
\text { Eu vou representar os vários carbonos assim // Carbono hidrogênio, } \\
\text { tudo bem? }\end{array}$ & $\begin{array}{l}\text { P2: Vocês já viram assim? Na ponta eu tenho um carbono, sempre } \\
\text { ligado a dois hidrogênios. Os hidrogênios, eu não coloco. Tudo bem? }\end{array}$ & Dêitico / Metafórico \\
\hline sd07.05 & $\begin{array}{l}\text { P2: Vou ter uma cadeia grande. No final da cadeia, eu tenho dupla O, } \\
\text { O- e Na+. }\end{array}$ & Sescrição Molecular \\
\hline sd07.06 & $\begin{array}{l}\text { P2: Esse aqui não é igual àquela molécula que a gente viu no (inaudível) } \\
\text { slide?// }\end{array}$ & Dêitico / Metafórico \\
\hline sd07.07 & P2: só que invés de tá carbono hidrogênio carbono hidrogênio// & Dêitico / Metafórico \\
\hline sd07.08 & P2: eu coloquei umas setinhas para ficar mais fácil. Tudo bem? & Icônico / Metafórico \\
\hline sd07.09 & &
\end{tabular}

Quadro 8. Codificação da operação epistêmica explicação no minicurso Sabões e detergentes.

\begin{tabular}{|c|l|c|c|}
\hline Turno & \multicolumn{1}{|c|}{ Transcrição - explicação } & Gestos epistêmicas \\
\hline sd06.07 & P2: Porque a eletronegatividades deles é igual/ & Dêitico \\
\hline sd06.08 & P2: o que um puxa o elétron para um lado, o outro puxa para o outro. & Metafórico \\
\hline sd06.09 & $\begin{array}{l}\text { P2: Quando eu mudo o elemento. Quando eu tenho o HCl. São } \\
\text { elementos diferentes. }\end{array}$ & Metafórico \\
\hline \multirow{2}{*}{ sd06.10 } & $\begin{array}{l}\text { P2: Quem é mais eletronegativo? } \\
\text { A: O Cl } \\
\text { P2: O Cl. Se ele é mais eletronegativo }\end{array}$ & Dêitico \\
\hline \multirow{2}{*}{ sd06.11 } & $\begin{array}{l}\text { P2: ele vai puxar mais os elétrons. Então vão ficar mais deslocados para } \\
\text { o lado dele, a gente fala que vai ficar mais ou menos assim a nuvem. } \\
\text { Certo? Ai eu vou ter um delta menos e um delta mais. }\end{array}$ & Icônico / Metafórico \\
\hline
\end{tabular}

A professora segue com a operação de explicação e relaciona o fenômeno de polaridade com a diferença de eletronegatividade do elemento (Quadro 8). Ela aponta para a molécula de $\mathrm{H} 2$, que tem elementos com mesma eletronegatividade, realizando um gesto metafórico de atrair o elétron em um sentido e de atrair no outro sentido apenas com a mão direita.

Em seguida, ela escreve a representação estrutural do cloreto de hidrogênio na lousa, permanecendo com a mão direita sobre ela e indica o $\mathrm{Cl}$ após dizer mais eletronegativo. Realiza um gesto icônico/metafórico com as duas mãos, mostrando o ato de atrair mais os elétrons da ligação química. Depois desenha na lousa a distribuição de elétrons com o formato de uma nuvem com uma região maior para o $\mathrm{Cl}$ e menor para $\mathrm{o} \mathrm{H}$.

Com o propósito de construir significados relacionados à tridimensionalidade do OM (Quadro 9), o professor utiliza aspectos como volume e profundidade da molécula, mas o faz de forma descontextualizada, caracterizando assim a generalização. Outro aspecto importante diz respeito aos tipos de gestos realizados (metafóricos), pois a descontextualização que ocorre na generalização confere a essa operação epistêmica um elevado grau de abstração, coexistindo no exemplo com a diminuição do caráter icônico dos gestos.

Quadro 9. Codificação da operação epistêmica generalização no minicurso Sacolas plásticas.

\begin{tabular}{|c|l|c|c|}
\hline Turno & \multicolumn{1}{|c|}{ Transcrição - generalização } & Gestos & Op. epistêmicas \\
\hline sd04.12 & P1: Mas a molécula, na verdade, é uma estrutura & Sem gestos \\
\hline sd04.13 & P1: que não é uma estrutura plana, que a gente já falou um pouquinho & Batimento \\
\hline sd04.14 & P1: Ela é uma estrutura que é representada em três dimensões & Metafórico \\
\hline sd04.15 & P1: ela tem um volume, ela tem uma profundidade & Metafórico \\
\hline sd04.16 & P1: e é um pouco difícil a gente representar isso em duas dimensões & Metafórico & \\
\hline
\end{tabular}


Quadro 10. Codificação da operação epistêmica definição no minicurso Sabões e detergentes.

\begin{tabular}{|c|l|c|c|}
\hline Turno & \multicolumn{1}{|c|}{ Transcrição - definição } & Gestos & Op. epistêmicas \\
\hline \multirow{2}{*}{ sd01.02 } & $\begin{array}{l}\text { P2: Sabão é um tipo mais simples de detergente. Como todo éster, } \\
\text { os óleos e gorduras sofrem hidrólise básica que, no caso dos lipídios, } \\
\text { é tradicionalmente chamado de saponificação. Então a reação para } \\
\text { formação do sabão é saponificação. }\end{array}$ & Sem gestos & Definição \\
\hline
\end{tabular}

\section{Codificação das operações epistêmicas}

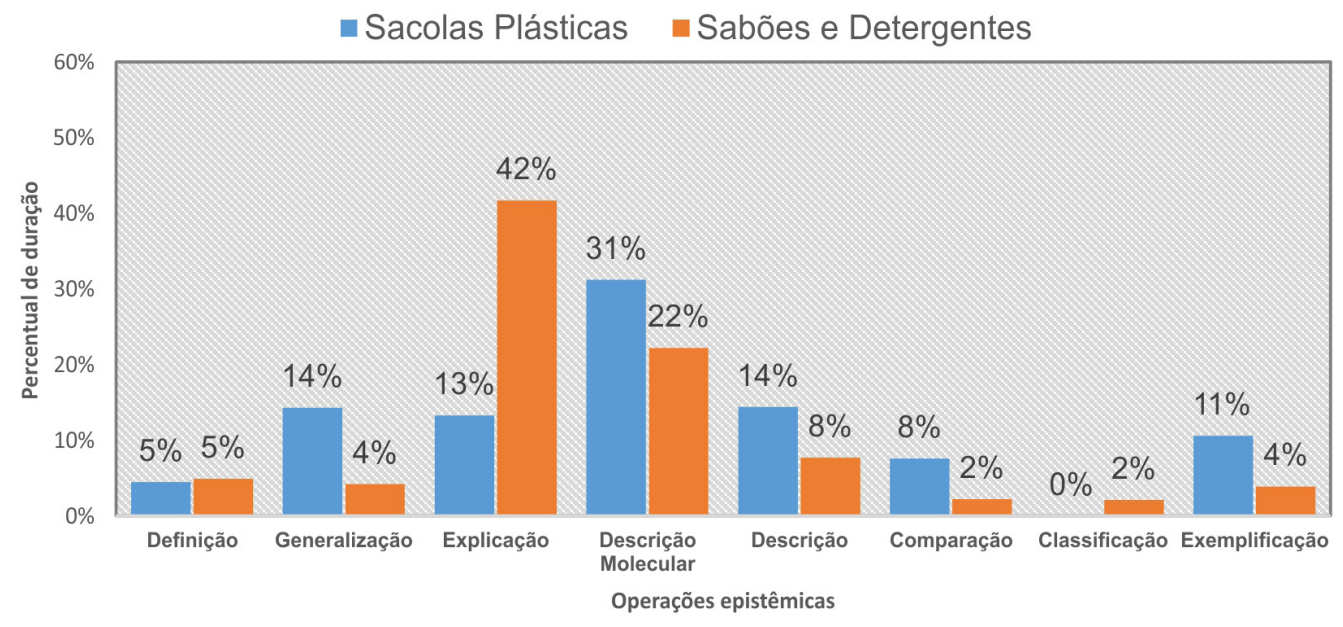

Figura 11. Percentual de codificação de operações epistêmicas nos minicursos Sabões e detergentes e Sacolas plásticas.

Partindo da definição de sabão, as representações deste são empregadas para explicar como acontece a reação de saponificação (Quadro 10). Em seguida, com o intuito de construir a resposta da forma ou do motivo da limpeza do sabão, a professora descreve situações em que este é usado, como para lavar roupa ou louça, além de problematizar sobre a possível contradição entre uma substância produzida a partir de gordura e sua propriedade de limpeza, o que dá margem à explicação.

Na Figura 11, apresentamos a distribuição da codificação das operações epistêmicas nos episódios Sacolas plásticas e Sabões e detergentes. Observa-se a utilização majoritária que a professora (P2) faz da categoria explicação (42\%), seguida da descrição molecular (22\%) e, em menor quantidade, as demais operações epistêmicas. No minicurso de sacolas plásticas, o professor (P1) apresenta maior uso da descrição molecular (31\%) e diversifica o uso das demais operações epistêmicas.

A professora realiza muitos gestos dêiticos e metafóricos e, por meio do Quadro 11, podemos inferir como estes foram realizados em função das diferentes operações epistêmicas. A operação de descrição não apareceu, pois não existiu gesto associado. A grande maioria dos gestos foi realizada com os propósitos de explicação e descrição molecular, sendo o gesto dêitico o mais frequente com 49 codificações, 32 para gestos metafóricos, 14 para gestos icônicos e 10 para gestos de batimento. Esse estilo com poucos batimentos indica que a professora estabelece pouca ênfase gestual para o discurso, utilizando prevalentemente os gestos dêiticos, metafóricos e icônicos, nessa ordem, para produzir significados com a representação estrutural.
Quadro 11. Matriz de codificação das categorias gestuais e epistêmicas no episódio do minicurso Sabões e detergentes.

\begin{tabular}{|l|c|c|c|c|}
\hline & Batimento & Dêiticos & Icônico & Metafórico \\
\hline Definição & 0 & 1 & 0 & 1 \\
\hline Generalização & 0 & 1 & 0 & 0 \\
\hline Explicação & 6 & 29 & 8 & 21 \\
\hline $\begin{array}{l}\text { Descrição } \\
\text { molecular }\end{array}$ & 1 & 16 & 3 & 8 \\
\hline Exemplificação & 3 & 2 & 3 & 2 \\
\hline
\end{tabular}

Os gestos dêiticos da professora estão associados principalmente à explicação (29) seguida da descrição molecular (16). Os gestos metafóricos estão associados à explicação (21) e em menor presença à descrição molecular (8). Os gestos icônicos (14) e de batimento (10) aparecem em menor proporção no total. Com isso, a concentração dos gestos envolve a descrição molecular e a explicação, sendo que esta é sempre mais gestual que aquela. Nesse episódio, podemos inferir que os gestos da professora estão associados à operação de explicação.

No minicurso de sacolas plásticas, o professor realiza gestos com grande multiplicidade de propósitos, sendo possível perceber no Quadro 12 a diversificação desses gestos em função das operações epistêmicas realizadas. Os gestos dêiticos aparecem associados à descrição molecular (38) em momentos que o professor generaliza (10), compara (9) e exemplifica (7); gestos metafóricos se destacaram na associação com a categoria 
generalização (16); e gestos icônicos estiveram relacionados principalmente à descrição molecular (18) e à generalização (6).

Os gestos de batimento perpassaram todas as operações epistêmicas no total de 63 relações, e a maior parte destes está relacionada ao estado emocional, possivelmente nervosismo, o que leva ao uso pronunciado desse tipo de gesto (Silva-Neto; Aizawa; Giordan, 2013).

Quadro 12. Matriz de codificação das categorias gestuais e epistêmicas no episódio do minicurso Sacolas plásticas.

\begin{tabular}{|l|c|c|c|c|}
\hline & Batimento & Dêitico & Icônico & Metafórico \\
\hline Definição & 4 & 1 & 0 & 4 \\
\hline Generalização & 8 & 10 & 6 & 16 \\
\hline Explicação & 13 & 3 & 1 & 4 \\
\hline Comparação & 5 & 9 & 0 & 2 \\
\hline $\begin{array}{l}\text { Descrição } \\
\text { molecular }\end{array}$ & 16 & 38 & 18 & 3 \\
\hline Descrição & 14 & 3 & 0 & 1 \\
\hline Exemplificação & 3 & 7 & 3 & 3 \\
\hline
\end{tabular}

No cômputo total de gestos, o professor utilizou maior quantidade do que a professora. Para ele, os gestos foram distribuídos nas sete operações epistêmicas, enquanto que, para ela, três operações são predominantes. Os gestos do professor concentraram-se na descrição molecular. Além disso, podemos correlacionar seus gestos dêiticos e icônicos com o propósito de descrever o OM. No caso dela, o propósito esteve relacionado à explicação do conceito de polaridade de substâncias.

A comparação entre os Quadros 11 e 12 indica uma considerável diferença dos padrões gestuais associados a operações epistêmicas de cada professor, os quais são característicos das suas atuações ou estilos de ensinar mediados pela representação estrutural química. Fatores como densidade e co-ocorrência gestual podem estar associados a diversos aspectos da formação inicial de professores. Nesse sentido, é possível inferir que a gestualidade do professor de química é uma característica importante em sua formação e, portanto, deve ser investigada, sobretudo quando se refere aos movimentos epistêmicos realizados com a mediação da REQ.

\section{Considerações finais}

A combinação entre categorias gestuais e operações epistêmicas é uma metodologia que oferece um mapeamento dos processos cognitivos em sala de aula. Com os cruzamentos, é possível caracterizar a execução de atividades de ensino que são determinadas pelos propósitos do professor. Os resultados indicam a existência de relações entre os tipos de gestos realizados pelos professores e as operações epistêmicas, por exemplo, e gestos metafóricos estão frequentemente associados a operações epistêmicas abstratas, como generalização e explicação. De forma semelhante, gestos icônicos estão associados a operações epistêmicas menos abstratas como a descrição molecular. Na categoria exemplificação, não foi possível observar diferença entre os tipos de gestos que são realizados pelos professores, pois houve distribuição semelhante entre eles. Não foi possível estabelecer relação direta entre a operação epistêmica de comparação com os gestos icônicos e metafóricos, pois esta pode se referir tanto a um referente específico quanto a um referente abstrato na categorização de Silva e Mortimer (2010).

Todavia, os resultados também indicam que os professores atuam de maneiras distintas e apresentam padrões característicos no uso de gestos, que se modificam de acordo com os propósitos de ensino. Para a professora, seu propósito prevalecente foi explicar a ação de limpeza dos sabões e detergentes, por isso, a representação estrutural esteve associada aos gestos dêiticos e metafóricos. Já para o professor, prevaleceu o propósito de descrever a estrutura química dos plásticos com gestos dêiticos e icônicos. As variações e correlações entre as categorias no decorrer da aula possibilitam analisar os movimentos discursivos e compará-los com o planejamento de ensino elaborado pelos professores em formação inicial. Esse é um estudo potencialmente importante para analisar a transição entre o planejamento e a execução de atividades de ensino, aspecto de destaque nas complexas relações teoria, metodologia e prática de ensino.

Silva e Mortimer (2010) sugerem a ocorrência de um movimento de descontextualização ou recontextualização do discurso escolar associados às mudanças de operações epistêmicas menos abstratas, como descrição e explicação, para operações epistêmicas mais abstratas, como generalização e definição. Além disso, enfatiza a relação das operações epistêmicas com os tipos de referentes (específico ou abstrato) e a modelagem (mundo dos objetos e eventos e mundo das teorias e dos modelos). Já em nossa pesquisa, os propósitos de ensino do professor associados às operações epistêmicas são analisadas por meio da co-ocorrência de categorias gestuais de McNeill (2005) em situações cuja REQ está em evidência. A metodologia estabelecida permite a identificação de sobreposições categóricas que podem resultar em combinações híbridas. Na hibridização, observam-se, por exemplo, aspectos de ambas as categorias. A hibridização icônico/ metafórico possui tanto o aspecto do gesto icônico como do metafórico. Nesses casos, não é possível delimitar claramente as fronteiras entre eles.

Do ponto de vista quantitativo, os relatórios de codificação de categorias produzidos pelo software Nvivo forneceram informações sobre duração, frequência e sobreposição das categorias, as quais se mostraram bons parâmetros para a análise. Neste estudo, identificamos alto potencial dessas informações para descrever os episódios de ensino e o estilo de combinação de gestos, suporte, posicionamento e fala do professor. Os dados quantitativos também têm sido empregados para desenvolver 
critérios de seleção de sequências discursivas de episódios de ensino em estudos do nosso laboratório.

Outra implicação desta pesquisa diz respeito às práticas docentes, cujos desdobramentos dão origem a outras questões: quais seriam os impactos da consciência gestual no planejamento do professor? Como a produção de significados pode ser investigada levando em consideração aspectos gestuais e epistêmicos? É evidente que não almejamos desenvolver planos de ensino com requisitos gestuais para sua elaboração. No entanto, as operações epistêmicas relacionadas aos diversos modos semióticos, como os gestos, são passíveis de promover a reflexão sobre como ocorre a produção de significados, o que permite estabelecer relações entre a atuação do professor em sala de aula e o conhecimento químico que ali se constrói.

\section{Referências}

ABDOOLATIFF, S.; NAROD, F.B. Investigating the effectiveness of computer simulations in the teaching of atomic structure and bonding. In: GUPTA-BHOWON, M. et al. (Eds.). Chemistry education in the ICT age. New York: Springer, 2009. p. 85-100.

AIZAWA, A.; SILVA-NETO, A.B.; GIORDAN, M. Análise dos modos semióticos de representação estrutural química: categorias emergentes na formação inicial de professores. In: GALIETA, T.; GIRALDI, P.M. (Orgs.). Linguagens e discursos na educação em ciências. Rio de Janeiro: Multifoco, 2014. p. 375-390.

ARAÚJO-NETO, W.N. A noção clássica de valência e o limiar da representação estrutural. Cadernos Temáticos de Química Nova na Escola, 7, p 13-24, 2007.

Formas de uso da noção de representação estrutural no ensino superior de química. 2009. Tese (Doutorado em Educação) Universidade de São Paulo, São Paulo, 2009.

BOLTON, K.; SAALMAN, E. CHRISTIE, M.; INGERMAN, A. LINDER, C. SimChemistry as an active learning tool in chemical education. Chemistry Education Research and Practice, v. 9, n. 3, p. 277-284, 2008.

DORI, Y. J.; BARAK, M. Computerized molecular modeling: enhancing meaningful chemistry learning. In: INTERNATIONAL CONFERENCE OF THE LEARNING SCIENCES, 4, 2000. Proceedings... p. 185-192, 2000.

FRAILICH, M.; KESNER, M.; HOFSTEIN, A. Enhancing students' understanding of the concept of chemical bonding by using activities provided on an interactive website. Journal of Research in Science Teaching, v. 46, n. 3, p. 289-310, 2009.

GILBERT, J.K. The role of visual representations in the learning and teaching of science: an introduction. Asia-Pacific Forum on Science Learning and Teaching, v. 11, p. 1-19, 2010.

GIORDAN, M. Computadores e linguagens nas aulas de ciências. Ijuí: Ed. Unijuí, 2013.

GOIS, J.; GIORDAN, M. Semiótica na química: a teoria dos signos de Peirce para compreender a representação estrutural. Cadernos Temáticos de Química Nova na Escola, 7, p. 34-42, 2007.
JIMENEZ-ALEIXANDRE, M.P.; DIAZ, J.B.; DUSCHL, R.A. Scientific culture and school culture: epistemic and procedural components. In: NATIONAL ASSOCIATION FOR RESEARCH IN SCIENCE TEACHING (NARST), San Diego, p. 1-24, 1998.

KEIG, P.F.; RUBBA, P.A. Translation of representations of the structure of matter and its relationship to reasoning, gender, spatial reasoning, and specific prior knowledge. Journal of Research in Science Teaching, v. 30, n. 8, p. 883-903, 1993.

KELLY, G.J. Inquiry, activity, and epistemic practice. In: INQUIRY CONFERENCE ON DEVELOPING A CONSENSUS RESEARCH AGENDA. New Brunswick, 2005.

KENDON, A. Gesture: visible action as utterance. Cambridge: Cambridge University Press, 2004.

KRESS, G.; JEWITT, C.; OGBORN, J.; TSATSARELIS, C. Multimodal teaching and learning: the rhetorics of the science classroom. London: Continuum, 2001.

MARTINS, I.; PICCININI, C.L. Comunicação multimodal na sala de aula de ciências: construindo sentidos com palavras e gestos. Ensaio: pesquisa em ensino de ciências, v. 6, n. 1, p. 1-14, 2004.

MCNEILL, D. Gesture and thought. Chicago: University of Chicago Press, 2005.

PEREIRA, R.R.; MORTIMER, E.F.; MORO, L. A importância do uso de diferentes tipos de gestos em aulas de química orgânica do ensino superior. In: ENCONTRO NACIONAL DE PESQUISA EM EDUCAÇÃO EM CIÊNCIAS (ENPEC), 9, 2013. Atas... p. 1-8, Águas de Lindoia, 2013.

PING, R.; GOLDIN-MEADOW, S. Gesturing saves cognitive resources when talking about nonpresent objects. Cognitive Science, v. 34, p. 602-619, 2010.

QUADROS, A.L.; MORTIMER, E.F. Linguagem multimodal: as aulas do professor de ensino superior. In: ENCONTRO NACIONAL DE ENSINO DE QUÍMICA (ENEQ), 15, 2010. Atas... Brasília, 2010.

QUADROS, A.L.D.; SILVA, A.C.A.; MARTINS, D.A.A.; SÁ, E.F.; MORO, L.; SILVA, P.S; PEREIRA, R.R.; MARTINS, R.F; REIS, R.C.; MORTIMER, E.F. Interações multimodais em aulas de química do ensino superior. In: ENCONTRO NACIONAL DE ENSINO DE QUÍMICA (ENEQ), 16, 2012. Atas... p. 1-12, 2012.

SILVA, A.C.T. Estratégias enunciativas em salas de aula de química: contrastando professores de estilos diferentes. 2008. Tese (Doutorado em Educação) - Universidade Federal de Minas Gerais, Belo Horizonte, 2008.

SILVA, A.C.T.; MORTIMER, E.F. Caracterizando estratégias enunciativas em uma sala de aula de química: aspectos teóricos e metodológicos em direção à configuração de um gênero do discurso. Investigações em Ensino de Ciências, v. 15, p. 123-153, 2010.

SILVA-NETO, A.B; AIZAWA, A.; GIORDAN, M. Caracterizando a performance gestual em aulas de química. In: ENCONTRO PAULISTA DE PESQUISA EM ENSINO DE QUÍMICA (EPPEQ), 7, 2013. Atas... Santo André, 2013.

SOUZA, K.A.F.D.D.; PORTO, P.A. Elementos da semiótica peirceana na educação em química: considerações e possibilidades. In: ENCONTRO NACIONAL DE ENSINO DE QUÍMICA (ENEQ), 15, 2010. Anais... Brasília, 2010. 
URHAHNE, D.; NICK, S.; SCHANZE, S. The effect of threedimensional simulations on the understanding of chemical structures and their properties. Research in Science Education, v. 39, n. 4, p. 495-513, 2009.

VIANA, H.E.B.; PORTO, P.A. O processo de elaboração da teoria de John Dalton. Cadernos Temáticos de Química Nova na Escola, n. 7, p. 4-12, 2007.

VIGOTSKI, L.S. A construção do pensamento e da linguagem. 2. ed. São Paulo: Martins Fontes, 2009.
WARTHA, E.J.; REZENDE, D.B. Os níveis de representação no ensino de química e as categorias da semiótica de Peirce. Investigações em Ensino de Ciências, v. 16, p. 275-290, 2011.

WERTSCH, J.V. Mind as action. New York: Oxford Univ. Press, 1998. WU, H.; KRAJCIK, J.S.; SOLOWAY, E. Promoting understanding of chemical representations: students' use of a visualization tool in the classroom. Journal of research in science teaching, v. 38, n. 7, p. 821-842, 2001. 